África (São Paulo, 1978, Online), São Paulo, n. 35, p. 11-17, 2015

\title{
Introdução \\ Quarenta anos depois das independências dos PALOPs - Problemas historiográficos da África colonial portuguesa
}

Michel Cahen*

Este dossiê da Revista África publica uma parte das contribuições a um colóquio que foi promovido pelo Centro de estudos africanos da Universidade de São Paulo, realizado em 11 de outubro de 2013 sobre "Problemas Historiográficos da África Colonial Portuguesa e da África Pós-colonial de Língua Oficial Portuguesa", que contou com a presença, como moderadoras, das professoras Margarida Petter, Leila Leite Hernandez, Marina de Melo e Souza, as três da USP, bem como de Michel Cahen como coordenador. Tratava-se de voltar-se sobre alguns grandes debates tais como foram tratados na bibliografia recente ou menos recente. Obviamente, um dossiê em revista nunca poderia ser completo nesta ambição. Quisemos aproximarmo-nos dela por pequenas pinceladas sucessivas.

A primeira pergunta foi a de justificar um evento sobre a África de antiga colonização portuguesa. Com efeito, como muito bem o reparou o malogrado Patrick Chabal, essa África não deve ser, em geral, analisada como "ex-portuguesa" na medida em que $90 \%$ do seu território se tornou "português" somente a partir da Primeira Guerra Mundial, e parou de sê-lo sessenta anos mais tarde. Essa África é muito mais "banta", ou "oeste-africana" ou até "crioula" do que "ex-portuguesa". ${ }^{2}$ E também é muito verdade que os laços de Angola e Moçam-

\footnotetext{
* Diretor de pesquisa do CNRS, Cátedras francesas, USP/ Centro de pesquisa "Les Afriques dans le monde", Sciences Po Bordeaux, CNRS.

2 Patrick CHABAL, A History of Postcolonial Lusophone Africa. Bloomington (IN): Indiana University Press, 2002. P. Chabal faleceu em 2014.
} 
bique com o resto da África austral, da Guiné-Bissau e de Cabo Verde com a África ocidental são mais importantes, em termos culturais e civilizacionais, do que com a antiga potência colonial. Até se pode reparar que Moçambique se tornou membro da CPLP (Comunidade dos Países de língua portuguesa) só depois de aderir à Commonwealth, que São Tomé e Príncipe, Guiné-Bissau e Cabo Verde fizeram da mesma forma depois de ter aderido à Organização Internacional da Francofonia e que Angola atrasou a formação da CPLP para obter o máximo de cedências políticas de Portugal, suspeito de simpatia para com a Unita.' Logo, não se deve exagerar o peso das ligações com Portugal e se pode dizer a mesma coisa das relações com Brasil. Como dizia o escritor moçambicano Mia Couto citado por Alfredo Margarido², "mesmo falando português, um moçambicano estará sempre mais perto de um sul-africano ou de um zimbabuano [sic] do que dos portugueses, brasileiros ou cabo-verdianos". ${ }^{3}$

Portanto, não há razão, por ser o Brasil um país de língua portuguesa, se interessar, pelo menos no plano científico, mais pelos países africanos de língua oficial portuguesa (PALOPs) do que pelo resto da África. É obviamente a mesma coisa em Portugal. Aliás, todos os colegas portugueses aprovam esta posição de princípio, mas logo acrescentam: “... só que ninguém faz”. Sem dúvida, $90 \%$ da pesquisa portuguesa em ciências sociais sobre África incidem sobre os PALOPs.

A situação é diferente no Brasil, talvez não por razões melhores, mas porque os mitos africanos no Brasil datam de um período em que os domínios costeiros e escravistas portugueses na África estavam mais espalhados geograficamente do que hoje: Casamança, Acra, a costa a oeste e leste de São João Baptista de Ajuda (hoje no Benim), Lagos, Congos... Os escravos vieram de inúmeras áreas na África, embora haja zonas majoritárias. Depois, os esforços de Roger Bastide ou Pierre Fatumbi Verger para "encontrar o Brasil em África" a todo

\footnotetext{
A União para a Independência Total de Angola fomentou uma terrível guerra civil contra a regime do MPLA (Movimento Popular de Libertação de Angola) de 1975 até 2002 e Mário Soares, presidente da República portuguesa (9 de março de 1986/9 março de 1996) foi acusado repetidamente pela MPLA de apoiar a Unita. A CPLP foi criada a 16 de julho de 1996.

2 Veja também a entrevista de Mia COUTO, "A lusofonia é uma ideia de políticos, num projeto que não é de todos nós”, In: Savana (Maputo), 12 de dezembro de 2014.

3 Alfredo MARGARIDO, A lusofonia e os lusófonos. Lisboa: Edições Universitárias Lusófonos, 2000, p. 71. Neste ensaio, A. Margarido não dá a fonte exata da declaração de Mia Couto, mas ela foi feita depois das reações portuguesas hostis quando Moçambique anunciou a adesão à Commonwealth.
} 
África (São Paulo, 1978, Online), São Paulo, n. 35, p. 11-17, 2015

http://dx.doi.org/10.11606/issn.2526-303X.v0i35p11-17

o custo fortaleceram uma ligação, na pesquisa histórica e antropológica, entre o Brasil e uma zona de África onde se encontravam os ditos "afro-brasileiros", ou Agudás, do Benim, do Togo e de Lagos. Mas é um fato que a pesquisa brasileira, em particular histórica, linguística, geográfica e antropológica sobre África incida em muitas zonas que nunca foram portuguesas. Provavelmente, a lei $\mathrm{n}^{\mathrm{o}} 10.639$ de 2003, que tornou obrigatório o ensino da história e da cultura afro-brasileira e africana nos programas das escolas primárias e secundárias, permitiu alargar um bocadinho o leque de aéreas estudadas, embora a "viragem africana" nas ciências sociais tivesse ficado limitada às disciplinas de História e Antropologia (não se sabe de nenhum recrutamento de mais professores especialistas da África nas Ciências Políticas, na Sociologia, Demografia, Geografia, Economia, no Direito, na Literatura ${ }^{4}$, etc., nas universidades brasileiras depois de 2003). A África parece assim ficar uma coisa do passado (história) ou de selvagens (antropologia). Podemos lembrar o caso de um estudante de sociologia na USP, que, muito recentemente, queria pesquisar sobre a África e a quem foi aconselhado por um docente ir para a antropologia "visto se tratar da África"...

O que enfraqueceu também a pesquisa africanista no Brasil é a confusão permanente com os estudos afro-brasileiros. Quando se olha para o conteúdo da pesquisa de alguns centros de "estudos africanos e afro-brasileiros", constata-se que mais ou menos $80 \%$ do que se faz é relativo ao Brasil e não à África e a lei de 2003 não parece capaz de modificar muito isso. A construção do conceito de afro-brasilidade é relativamente recente e incide mais nos meios da militância cultural e política do que na consciência popular. ${ }^{5}$ Se o trato dos viventes de África para as Américas obviamente faz parte da história da África, já os estudos sobre a vida dos escravos no Brasil, gerações depois da chegada deles, não incide sobre África, nem sobre Africanos - a não ser que fiquemos numa

\footnotetext{
4 Embora o caso da literatura seja um pouco diferente: no quadro das literaturas de língua portuguesa, há um certo desenvolvimento dos estudos sobre as literaturas dos PALOPs; mas será que os estudos sobre outras literaturas africanas (em línguas coloniais ou línguas africanas) se desenvolveram muito a partir de 2003?

5 Lembremos que houve movimentos negros para afirmar a ruptura completa com a África: veja, por exemplo, Marina Pereira de Almeida MELLO, Não Somos Africanos Somos Brasileiros: Identidade nos jornais do povo negro e dos imigrantes. São Paulo: Annablume, 2014, 244p. Quando Raimundo Nina Rodrigues escreveu nos princípios do século xx o seu livro Os Africanos no Brasil, tratava-se explicitamente e exclusivamente dos escravos de primeira geração, vindos da África, que ele pôde ainda encontrar na Bahia no final do século XIX. Já a primeira geração nascida no Brasil, chamava-a de crioula (Raimundo NINA-RODRIGUES, Os africanos no Brasil, revisão e prefácio de Homero Pires, São Paulo, Companhia Editora Nacional, 1935, 410 p.).
} 
Introdução

visão primordialista onde o "sangue" é que faz a identidade - porque, precisamente, a escravatura no contexto do Brasil colônia produziu novas identidades americanas. Por mais fortes razões, isto é verdade para os brasileiros negros dos tempos de hoje. $\mathrm{O}$ combate contra o racismo, contra os mitos da democracia racial para a recuperação da dignidade, para a igualdade, explica o aparecimento da expressão "afro-brasileiros", mas esta não deve ser entendida como significando uma "mistura" entre África e Brasil: trata-se da produção social de uma identidade dentro do Brasil, uma produção brasileira, com reinterpretação e reconfiguração das heranças africanas. Velho e acalorado debate...

Por aqui, queremos somente dizer que a pesquisa sobre África, sobre o continente africano, sobre os africanos do hoje, deve dissociar-se dos estudos afro-brasileiros para se desenvolver. Passos importantes foram realizados neste sentido, alguns já antigos com a criação do Centro de estudos africanos da Universidade de São Paulo em 1965, cuja orientação era decididamente devotada para a África ${ }^{6}$; mais recentemente com a criação do Núcleo de Estudos Africanos da Universidade Federal Fluminense formalizado em 2006, de mesma orientação; com o nascimento em 2011 do Grupo de trabalho sobre história de África na ANPUH que congrega hoje centenas de pessoas; e em 2012 do Centro de estudos africanos da Universidade federal de Minas Gerais. Muito recentemente, em setembro de 2014, ocorreu o nascimento da "Associação brasileira de estudos africanos/Abe-África" aberta a todos os estudiosos sobre África, histórias, culturas e experiências africanas, a partir de quaisquer disciplinas acadêmicas ou interesses profissionais. Mesmo se a ligação com os estudos afro-brasileiros deverá necessariamente manter-se, o enfoque está decididamente posto no continente africano. E o mais importante é sem dúvida o número importante de mestrados e doutorados em preparação sobre temáticas africanas nas ciências sociais, ainda principalmente nas disciplinas de história e antropologia, mas já com alguns poucos exemplos em sociologia, ciências políticas, relações internacionais (sem falar da literatura). Se a tendência permanecer, não há dúvida de que, daqui a quinze anos, Brasil tornar-se-á um dos principais

\footnotetext{
Pode-se comparar com os nomes de outros centros entre os mais antigos: o Centro de Estudos Afro-Orientais da Universidade Federal da Bahia, criado em 1959 ; o Instituto Brasileiro de Estudos Afro-Asiáticos (IBEA) criado em 1961 e extinto em 1964, mas retomado em 1973, na Universidade Cândido Mendes (RJ), como Centro de estudos Afro-Asiáticos.
} 
África (São Paulo, 1978, Online), São Paulo, n. 35, p. 11-17, 2015

http://dx.doi.org/10.11606/issn.2526-303X.v0i35p11-17

países do mundo em matéria de pesquisa sobre a África. E não parece que essa África será somente a África de língua oficial portuguesa.

Voltemos, pois, à pergunta inicial: por que publicar um dossiê sobre a África de anterior colonização portuguesa? A resposta afinal é simples: é uma questão de medida. Não é sã, como já dissemos, que em Portugal $90 \%$ da pesquisa sobre África incidam somente sobre as antigas colônias de Portugal na África no século xx, quando já faz muito que não é o caso na Inglaterra ou na França relativamente às Áfricas ditas anglófonas e francófonas. Também se pode dizer que mais vale publicar estudos sobre Moçambique, por exemplo, no quadro de uma coletânea sobre África austral, ou sobre Cabo Verde num livro sobre a CEDEAO, etc. Tudo isso faz muito sentido. Mas em contrapartida, quem vai negar que o "século curto" da colonização portuguesa contemporânea na África" também não criou pontos comuns, ou mesmo diferenças entre as colônias, mas produzidas pela heterogeneidade da própria colonização portuguesa, que não foi a mesma na Guiné-Bissau ou Cabo Verde, em São Tomé ou Angola, etc.? Pois, no quadro de um desenvolvimento geral da pesquisa sobre África no Brasil, faz todo o sentido, de vez em quando, trabalhar sobre o conjunto das antigas colônias portuguesa da África.

A isso acrescentaremos a efeméride, na medida em que o ano de 2015 marca os quarenta anos das independências nos PALOPs em 1974-75², isto é mais ou menos a duração de uma geração. Hoje em dia, a maioria da população dos PALOPs nasceu depois das independências, o que é um fator político de primeira importância para a evolução desses países.

Já não estamos no "pós-colonial", mas no "pós-pós-colonial”... Isto pode criar condições melhoradas para o retomar de análises sobre o período colonial: não se trata mais de denunciar a colonização portuguesa - ela foi definitivamente condenada pela história - mas, sem abandonar nada no pensamento anticolonialista e decolonial de se aproximar de uma maneira mais e mais científica das problemáticas deste período colonial. ${ }^{9}$

\footnotetext{
7 Pode-se considerar que a segunda “idade colonial” de Portugal na África comece em 1878 com a proibição da escravatura, e acabe obviamente em 1974-1975.

8 A Guiné-Bissau proclamou a sua independência ao 24 de setembro de 1973, reconhecida por Portugal ao 10 de setembro de 1974. Os outros quatro PALOPs obtiveram todos a sua independência em 1975: 25 de junho (Moçambique), 5 de julho (Cabo Verde), 12 de julho (São Tomé e Príncipe), 11 de novembro (Angola).

9 Embora a chamada para o colóquio organizado pelo CEA-USP em setembro de 2013 incidisse sobre
} 
Os artigos publicados neste dossiê vão neste sentido. Como já foi dito, constituem algumas pinceladas para avançar na história da história do período colonial português contemporâneo na África. Todas as colônias são mais ou menos presentes, através da discussão de problemas historiográficos muito diversos: as classificações étnicas no contexto de mudanças políticas e sociais importantes no caso de Hector Guerra Hernandez ("Invasões estrangeiras e formação do estado ao sul de Moçambique"); uma reinterpretação dos fenômenos de conversão ao cristianismo no caso de Iracema Dulley ("A historiografia sobre a "conversão" nas colônias portuguesas na África e a trajetória de Jesse Chiula Chipenda"); as dificuldades de Portugal para com os antropólogos mesmo antes da eclosão das lutas de libertação, no caso de Lorenzo Macagno ("Antropólogos na "África portuguesa": história de uma missão secreta"); uma "ficção historiográfica" - isto é a reconstituição de uma trajetória social com base na documentação e bibliografia disponível - sobre uma vida de indígena no tempo do trabalho forçado em Angola no caso de Maria da Conceição Neto ("Maria do Huambo: uma vida de “indígena'. Colonização, estatuto jurídico e discriminação racial em Angola (1926-1961)”); uma crítica a estudos sobre trabalho forçado no Império português de África (continental), no caso de Michel Cahen ("Seis teses sobre o trabalho forçado no império português continental em África").

Quarenta anos depois das independências dos PALOPs, a pesquisa sobre o período colonial continua enriquecendo-se. E continua obviamente com os pesquisadores desses países: se este dossiê inclui somente um deles (Angolana), é porque ele é em primeiro lugar o produto de um modesto colóquio tido na universidade de São Paulo, sem os meios para poder convidá-los. Mas que fique aqui dito: se a pesquisa científica não tem nacionalidade nem cor, se isto quer dizer que artigos escritos sobre a África por autores não africanos têm

\footnotetext{
o período colonial como pós-colonial, a grande maioria das contribuições trataram do período colonial e finalmente a totalidade dos artigos agora publicados nessa coletânea trata da historiografia da época colonial. Talvez discutir da historiografia da "história imediata" ou "história do tempo presente" pusesse dificuldades específicas. No entanto, pelo menos para o caso de Moçambique pós-colonial, pode se ver Alice DINERMAN, Revolution, Counter-Revolution and Revisionism in Postcolonial Africa. The Case of Mozambique, 1975-1994, New York, Oxon, Routledge, 2006; Michel CAHEN, “À la recherche de la défaite. Notes sur une certaine historiographie de la "révolution" et de la "contre-révolution", au Mozambique et sans doute ailleurs", Politique Africaine (Paris, Karthala), 2008, n 112, p. 161-181.
} 
África (São Paulo, 1978, Online), São Paulo, n. 35, p. 11-17, 2015

http://dx.doi.org/10.11606/issn.2526-303X.v0i35p11-17

uma legitimidade igual aos que autores africanos podem escrever, também é óbvio que, cada vez que isso for possível, as publicações devem tentar combinar autores de várias nacionalidades, africanas e não africanas. Além disso, neste mundo neoliberal onde a pesquisa é um mercado como qualquer outro, e onde os pesquisadores são avaliados não só pela sua capacidade em publicar rapidamente (o famoso "publish or perish") mas também (e talvez sobretudo) em publicar em "revistas internacionais" (isto é, revistas de língua inglesa), é bom, para autores não africanos aceitar publicar em revistas africanas que não constam das grandes listas internacionais das ditas revistas "A", sem que isso fosse sentido como um "sacrifício". É o nosso dever de pesquisadores e é enriquecedor colaborarmos na construção de ferramentas científicas comuns. ${ }^{10}$

Desejamos-lhe uma boa leitura e ficamos abertos a todas as críticas que os artigos aqui publicados poderão atrair."

\footnotetext{
10 É bom assinalar aqui a existência da Revista angolana de Sociologia, dirigida por Paulo de Carvalho, docente da Universidade Agostinho Neto, uma revista que já conta 17 números, cuja redação está em Angola e a editora em Portugal (Edições Pedago), que pratica inflexivelmente a regra da dupla avaliação cega com peritos internacionais e que está presente no grande site $<$ Revues.org $>$ : $<$ http://ras.revues.org $>$; também é de saudar a série de livrinhos "Cadernos de ciências sociais" publicada na Escolar Editora e que conta também 17 volumes, uma iniciativa de Carlos Serra, sociólogo na Universidade Eduardo Mondlane.

11 Fechando a última revisão deste texto de introdução (20 de Agosto de 2015), deparo-me com a notícia da publicação de um artigo de Lorenzo MACAGNO, de cuja referência passo a indicar: "Estudos africanos no Brasil: uma questão de afinidades eletivas?”, In Revista TEL, V (3), 2014 [publicação agosto de 2015]: 124-137. Segundo este artigo, de 1987 até 2009, foram defendidas 156 dissertações ou teses de pós-graduação sobre Cabo Verde (26), Moçambique (23), Angola (8) e Guiné-Bissau (8) ou África portuguesa em geral (18), em letras (32), história (32), antropologia (22), sociologia (19) (Levantamento preliminar realizado por Victor Miguel Castillo de Macedo (PIBIC/CNPq) com base em dados da CAPES). Isto faz uma media de menos de sete dissertações ou teses por ano, ainda muito baixa. Será muito interessante poder comparar com o decênio 2010-2020, com certeza superior.
} 